Кудрин А.С. О правовом и антиправовом воздействии социальных партнеров на общественные отношения в сфере применения наемного труда // Вестник ПНИПУ. Культура. История. Философия. Право. - 2017. - № 3. - С. 67-72. DOI: 10.15593/perm.kipf/2017.3.09

Kudrin A.S. About legal and anti-legal impact of social partners on social relations in the sphere of using of hired labour. Bulletin of PNRPU. Culture. History. Philosophy. Law, 2017, no. 3, pp. 67-72. DOI: 10.15593/perm.kipf/2017.3.09

ЮРИДИЧЕСКИЕ НАУКИ

DOI 10.15593/perm.kipf/2017.3.09

УДК 349.222

\author{
А.С. Кудрин \\ О ПРАВОВОМ И АНТИПРАВОВОМ ВОЗДЕЙСТВИИ \\ СОЦИАЛЬНЫХ ПАРТНЕРОВ НА ОБЩЕСТВЕННЫЕ ОТНОШЕНИЯ \\ В СФЕРЕ ПРИМЕНЕНИЯ НАЕМНОГО ТРУДА
}

\begin{abstract}
Выявлены позитивные и негативные проявления правового и антиправового воздействия (прежде всего нарушений трудового законодательства) социальных партнеров на трудовые отношения. Рассмотрены правовое регулирование отношений социального партнерства в сфере труда; некоторые нарушения трудового законодательства при заключении и реализации коллективных договоров и соглашений; способы предотвращения таких нарушений. Методологическую основу данного исследования составляет совокупность методов научного познания, среди которых ведущее место занимает диалектический метод. Использованы общенаучные (диалектика, анализ и синтез, абстрагирование и конкретизация) и частно-научные методы исследования (формально-юридический, сравнительно-правовой, технико-юридический). По мнению автора, социальные партнеры и профрсоюзы выступают субъектами социальной власти в трудовых отношениях. Их главное назначение состоит в ограничении произвола власти работодателей, предотвращении антиправового воздействия с их стороны для улучшения правового и социального положения работников. Вместе с тем возможно и антиправовое воздействие на трудовые отношения со стороны социальных партнеров. Профсоюзы, как объединения работников, выполняют защитную функцию, заключая коллективные договоры и соглашения, а также осуществляя контроль за соблюдением трудового законодательства.

Ключевые слова: правовое и антиправовое воздействие, социальные партнеры, профсоюзы, трудовые отношения, коллективный договор, соглашение.
\end{abstract}

\title{
A.S. Kudrin \\ ABOUT LEGAL AND ANTI-LEGAL IMPACT OF SOCIAL PARTNERS ON SOCIAL RELATIONS IN THE SPHERE OF USING OF HIRED LABOUR
}

In the modern period of development of Russian society and the state plays an important role in the Institute of social partnership in the labour sphere as a means of coordination of interests of hired labour and capital. Goals: to identify the positive and negative effects of legal and anti-legal impact (primarily labor law violations) of the social partners in labour relations. Tasks. The objectives of this paper are: consideration of legal regulation of relations of social partnership in the labour sphere; identifying some violations of labor law at the conclusion and implementation of collective contracts and agreements; identify ways to prevent such violations. Methods: a methodological basis for this study is a set of scientific methods, among which the leading place is the dialectical method. The article used General scientific methods (dialectic, analysis and synthesis, abstraction and concretization) and private-scientific methods (formal-legal, comparative legal, technical legal). Results. The author believes that social partners and trade unions are subjects of social power in labour relations. Their main purpose is to limit the arbitrary power of the employers, the prevention of anti-legal impact on their part to improve the legal and social situation of workers. Conclusions: trade Unions, workers associations, performing protective function in relation to the employer through collective bargaining and agreements, as well as through the implementation of control over observance of labour legislation.

Keywords: legal and illegal impact; social partners; trade Union; labour relations; collective agreement.

( С Кудрин Антон Сергеевич - кандидат юридических наук, доцент кафедры философии и права, ФГБОУ ВО «Пермский национальный исследовательский политехнический университет», e-mail: antoune@yandex.ru. 
В современный период развития российского общества и государства важную роль играет институт социального партнерства в сфере труда. Согласно ст. 23 Трудового кодекса Российской Федерации (далее - ТК РФ), «социальное партнерство в сфере труда - система взаимоотношений между работниками (представителями работников), работодателями (представителями работодателей), органами государственной власти, органами местного самоуправления, направленная на обеспечение согласования интересов работников и работодателей по вопросам регулирования трудовых отношений и иных непосредственно связанных с ними отношений» [2]. Таким образом, самым социальное партнерство в сфере труда следует рассматривать как сферу согласования интересов трех субъектов: работников, работодателей и публично-властных образований (государства и органов местного самоуправления).

Важно отметить, что право на объединение как правовая и организационная основа социального партнерства отражено как в Конституции Российской Федерации [1], так и в основополагающих международных актах [8].

Интересно и то, что на природу социального партнерства в научной литературе существуют различные точки зрения.

Так, В.А. Михеев, Б.П. Пономаренко считают, что социальное партнерство выступает «наиболее цивилизованной формой общественных отношений в социально-трудовой сфере, обеспечивающей согласование и защиту интересов органов государственной власти, работодателей (предпринимателей), работников и органов местного самоуправления на основе договора, достижения согласия, разработки и претворения в жизнь единой позиции по важнейшим направлениям политического и социально-экономического развития» [9, с. 20]. В.В. Комаровский полагает, что социальное партнерство представляет собой систему институтов, процедур и механизмов, с помощью которых устанавливается и поддерживается равновесие интересов сторон данных отношений, взаимодействующую с общественными интересами [5, с.10].

И. О. Снигирева справедливо отмечает, что «социальное партнерство - многоплановое явление, которое может быть охарактеризовано с политической, экономической, правовой точек зрения. По этой причине встречается различное понимание социального партнерства, его роли, целей и задач» [6, с. 73].

Проблема социального партнерства рассматривалась и в работах представителей пермской школы трудового права [3, с. 120-136].

Важно отметить, что социальные партнеры (представители работников и работодателей) способны оказывать правовое и антиправовое воздействие на трудовые отношения. Антиправовое воздействие может выражаться прежде всего в принятии коллективных договоров и соглашений, содержащих положения, противоречащие общепризнанным принципам и нормам международного права, трудовому законодательству и иным нормативным правовым актам, содержащим нормы трудового права, ухудшающим условия труда работников, снижающим уровень их правовых гарантий в сфере труда.

По мнению А.Е. Ефремова, к наиболее часто встречающимся нарушениям трудового законодательства можно отнести следующее: «в нарушение статьи 131 ТК РФ предусматривалась выплата заработной платы в неденежной форме в размере 50 \% от общей суммы заработной платы работника; устанавливались меры дисциплинарной ответственности работников, не предусмотренной в статье 192 ТК РФ (строгий выговор, снижение оплаты на 2 разряда водителям и механизаторам на период ремонта, сокращение ежегодного отпуска на количество дней прогула и т.д.); в нарушение статьи 91 ТК РФ для работников устанавливалась недельная норма рабочего времени продолжительностью 42 часа вместо 40, предусмотренных трудовым законодательством» [4, с. 72]. 
Наличие фактов принятия актов социального партнерства, ухудшающих правовое положение работников, подтверждается статистическими данными Государственной инспекции по Пермскому краю (далее - ГИТ). За 2016 год проверено 187 коллективных договоров и соглашений, выявлено 34 случая нарушения трудового законодательства. ГИТ по Пермскому краю при проведении контрольно-надзорных мероприятий уже в 2016 году выявила многочисленные нарушения законодательства при заключении коллективных договоров. Так, в ООО «Ремпутьмаш» в нарушение требований ст. 40 и 41, ч. 6 ст. 136 ТК РФ в коллективном договоре (п. 5.1.2 коллективного договора) установлен один день выплаты заработной платы, таким образом, в организации заработная плата выплачивается реже, чем каждые полмесяца. Также в ходе проверки другого предприятия ГИТ по Пермскому краю было установлено, что п. 5.1.3 коллективного договора организаций нарушает требования ст. 41 и 40, ч. 2 ст. 117 ТК РФ и Постановления Правительства Российской Федерации от 20. 11. 2008 г. № 870 «Об установлении сокращенной продолжительности рабочего времени, ежегодного дополнительного оплачиваемого отпуска, повышенной оплаты труда работникам, занятым на тяжелых работах, работах с вредными и (или) опасными и иными особыми условиями труда»; в коллективном договоре организации (п. 5.1.3 коллективного договора) предусмотрено предоставление «работникам, занятым на работах с вредными и (или) опасными условиями труда, согласно "Перечню работ, профессий и должностей, работа в которых дает право на дополнительный оплачиваемый отпуск” в размере 3, 7 и 9 календарных дней», вместо - не менее 7 календарных дней, положенных по законодательству, при установлении по результатам аттестации рабочих мест по условиям труда 3-го класса любой степени вредности») [11].

Аналогичные примеры трудового законодательства встречаются и в правоприменительной практике государственных инспекций в других субъектах Российской Федерации [12, 13].

В связи с этим показателен также и следующий пример. П. обратился в суд с иском к ОАО «Онежский лесопильно-деревообрабатывающий комбинат» (далее - ОАО «Онежский ЛДК») о признании незаконным дополнительного соглашения от 29 августа 2008 года к коллективному договору ОАО «Онежский ЛДК» от 22 мая 2002 года (далее - коллективный договор). Свои требования истец мотивировал тем, что был уволен с предприятия в связи с сокращением штатов. В соответствии с п. 6.1-6.4 коллективного договора он имел право на единовременное вознаграждение в размере трех средних месячных заработков и вознаграждение по итогам работы за год. Однако данная выплата ему не произведена, поскольку ее приостановили оспариваемым соглашением, принятым, по мнению истца, с нарушением норм Трудового кодекса Российской Федерации. Между тем коллективный договор предусматривал внесение изменений и дополнений к нему по соглашению его сторон лишь в случае повышения гарантий и прав работников. Кроме того, данное соглашение не зарегистрировано в установленном порядке. П. просил суд признать недействительным данное дополнительное соглашение.

Удовлетворяя иск, суд исходил из того, что приостановление действия некоторых положений коллективного договора на основании дополнительного соглашения от 29 августа 2008 года, заключенного между работодателем и профкомом без проведения процедуры согласования изменений, снижающих уровень прав и гарантий работников, является незаконным и влечет недействительность такого соглашения в силу ст. 50 ТК РФ.

Между тем трудовое законодательство не содержит понятия недействительности коллективного договора в целом или его отдельных положений, и в нем отсутствуют нормы о порядке признания коллективного договора (в целом либо его части) в качестве недействительного. 
Кроме того, в трудовом законодательстве отсутствуют нормы, позволяющие работнику оспорить в суде коллективный договор в порядке, установленном для разрешения индивидуальных трудовых споров.

Вместе с тем положения коллективного договора не могут быть признаны недействительными по иску отдельного работника, поскольку он не является стороной этого коллективного договора и не наделен правом [10].

Тем самым правовой заслон антиправовому воздействию видится главным образом в возвращении обязанности сторонам социального партнерства регистрировать коллективные договоры и соглашения. И лишь после этого данные акты социального партнерства обретут юридическую силу.

Необходимо отметить, что власть социальных партнеров в трудовых отношениях позитивно воздействует на трудовые отношения, улучшает правовое и материальное положение работников, обеспечивает сглаживание социальных противоречий и общественное развитие [7, с. 29].

Иллюстрацией служит Соглашение о минимальной заработной плате на 2017-2019 годы (Пермь, 11 ноября 2016 г., № СЭД-01-37-89), подписанное полномочными представителями правительства Пермского края, объединения организаций профсоюзов Пермского края «Пермский крайсовпроф» и регионального объединения работодателей Пермского края «Сотрудничество», предусматривающее установление размера минимальной заработной платы не ниже величины прожиточного минимума трудоспособного населения Пермского края [15].

Например, в рамках коллективного договора в ООО «ЛУКОЙЛ-ПЕРМЬ» предусмотрен целый комплекс различных социальных программ. Всего на его реализацию было направлено 584 млн рублей. В 2016 году 1205 сотрудников получили компенсации за путевки на сумму более 36 млн рублей, были выделены компенсации за отдых 1319 детей [14].

Таким образом, профсоюзы выступают субъектами социальной власти в трудовых отношениях. Их основное назначение состоит в представлении и защите интересов работников как наиболее экономически слабой стороны трудовых отношений. Вместе с тем возможно и антиправовое воздействие со стороны социальных партнеров на трудовые отношения. Профсоюзы как объединения работников выполняют защитную функцию работников путем установления коллективных договоров и соглашений, а также посредством осуществления контроля за соблюдением трудового законодательства.

\section{Список литературы}

1. Конституция РФ: принята всенародным голосованием 12 дек. 1993 г. Доступ из СПС «КонсультантПлюс».

2. Трудовой кодекс Российской Федерации: принят Государственной Думой 21 декабря 2001 г. Доступ из СПС «Консультант Плюс».

3. Бугров Л.Ю. Трудовой договор в России и за рубежом: моногр. / Перм. гос. нац. исслед. ун-т. - Пермь, 2013. - 642 с.

4. Ефремов А.В. О некоторых вопросах, связанных с разработкой и заключением коллективного договора // Право в Вооруженных силах. - 2012. - № 5. - С. 92-96.

5. Комаровский В.В. Становление системы социального партнерства как социального института в России // Социальное партнерство в переходном обществе: опыт России. - М., 1998. - С.7-9.

6. Комментарий к Трудовому кодексу Российской Федерации / под ред. К.Н. Гусова. М.: Проспект, 2006. - 928 с. 
7. Лушникова М.В. Государство, работодатели, работники: история, теория и практика правового механизма социального партнерства (сравнительно-правовые исследования). Ярославль: Подати, 1997. - 224 с.

8. Международная организация труда: конвенции, документы, материалы: справ. пособие. М.: ДиС, 2007. - 752 с.

9. Михеев В.А., Пономаренко Б. П. Государственная служба: регулирование конфликтов и социальное партнерство / Рос. акад. гос. службы. - М., 1996. - 55 с.

10. Определение Верховного суда РФ от 14 июня 2010 г. [Электронный ресурс]. - URL: http://dogovor-urist.ru/\%D (дата обращения: 17.12.2016).

11. Отчет о работе Государственной инспекции труда в Пермском крае за 2016 г. [Электронный ресурс]. - URL: http://git59.rostrud.ru/results/41487.shtml (дата обращения: 07. 05. 2017).

12. Официальный сайт Государственной инспекции труда в Приморском крае [Электронный ресурс]. - URL: http://git25.rostrud.ru/2858.shtml/xPages/entry.9220.html (дата обращения: 15.01.2017).

13. Официальный сайт прокуратуры Первомайского района Оренбургской области [Электронный ресурс]. - URL: http://pervomai.orenprok.ru/news-link/news/2014/03/17/pervomai14mart17/ (дата обращения: 15.01. 2017).

14. Реализация коллективного договора в ООО «ЛУКОЙЛ-Пермь». [Электронный реcypc]. - URL: http://permneft.lukoil-perm.ru/index.html?id=37\&parent_id=450\&eid=12 (дата обращения: 15.03.2017).

15.Соглашение между Правительством Пермского края, Объединением организаций профсоюзов Пермского края «Пермский крайсовпроф» и Региональным объединением работодателей Пермского края «Сотрудничество» о минимальной заработной плате в Пермском крае на 2017-2019 гг.: [заключено в г. Перми 11.11.2016 г., № СЭД-01-37-89] [Электронный pecypc]. - URL: http://www.consultant.ru/regbase/cgi/online.cgi?req=doc\&base=RLAW368\&n= 99177\#0 (дата обращения: 05.07.2017 г.).

\section{References}

1. Konstitutsiia Rossiiskoi Federatsii (priniata vsenarodnym golosovaniem 12.12.1993) [The Constitution of Russian Federation], available at: Konsul'tantPlius.

2. Trudovoi kodeks Rossiiskoi Federatsii ot 30.12.2001 № 197-FZ [RF Labour Code], available at: Konsul'tantPlius.

3. Bugrov L.lu. Trudovoi dogovor v Rossii i za rubezhom [Employment contract in Russia and abroad]. Perm', Permskii gosudarstvennyi natsional'nyi issledovatel'skii universitet, 2013, 642 p.

4. Efremov A.V. O nekotorykh voprosakh, sviazannykh s razrabotkoi i zakliucheniem kollektivnogo dogovora [About some issues related to the development and conclusion of a collective agreement]. Pravo v Vooruzhennykh Silakh, 2012, no. 5, pp. 92-96.

5. Komarovskii V.V. Stanovlenie sistemy sotsial'nogo partnerstva kak sotsial'nogo instituta v Rossii [Formation of system of social partnership as a social institution in Russia]. Sotsial'noe partnerstvo v perekhodnom obshchestve: opyt Rossii. Moscow, 1998, pp. 7-9.

6. Kommentarii k Trudovomu kodeksu Rossiiskoi Federatsii [The commentary to the Labour code]. Ed. K.N. Gusov. Moscow, 2006, 928 p.

7. Lushnikova M.V. Gosudarstvo, rabotodateli, rabotniki: istoriia, teoriia i praktika pravovogo mekhanizma sotsial'nogo partnerstva (sravnitel'no-pravovye issledovaniia) [The state, employers, workers: history, theory and practice of legal mechanism of social partnership (legal comparative research)]. Iaroslavl', Podati, 1997, 224 p.

8 Mezhdunarodnaia organizatsiia truda: konventsii, dokumenty, materialy [International Labour Organisation: conventions, documentary, materials]. Moscow, DiS, 2007, 752 p.

9. Mikheev V.A., Ponomarenko B. P. Gosudarstvennaia sluzhba: regulirovanie konfliktov i sotsial'noe partnerstvo [Public service: conflict management and social partnership]. Moscow, Rossiskaia akademiia gosudarstvennoi sluzhby, 1996, 5 5p.

10. Opredelenie Verkhovnogo suda RF ot 14 iiunia $2010 \mathrm{~g}$. [The Supreme court's determination], available at: http://dogovor-urist.ru/\%D (accessed 17 December 2016).

11. Otchet o rabote Gosudarstvennoi inspektsii truda v Permskom krae za $2016 \mathrm{~g}$. [The official website of the State labour inspection in the Perm region], available at: http://git59.rostrud.ru/results/41487.shtml (accessed 7 May 2017).

12. Ofitsial'nyi sait Gosudarstvennoi inspektsii truda v Primorskom krae. [The official website of the State labour inspection in the Primjrsky region], available at: http://git25.rostrud.ru/2858.shtml/xPages/entry.9220.html (accessed 15 January 2017). 
13. Ofitsial'nyi sait prokuratury Pervomaiskogo raiona Orenburgskoi oblasti [Official website of the Prosecutor's office of the Pervomaisky district of Orenburg region], available at: http://pervomai.orenprok.ru/news-link/news/2014/03/17/pervomai14mart17/ (accessed 15 Januay 2017).

14. Realizatsiia kollektivnogo dogovora v OOO «LUKOIL-Perm'» [The implementation of the collective agreement in LLC "LUKOIL-PERM], available at: http://permneft.lukoil-perm.ru/index.html?id=37\&parent_id=450\&eid=12 (accessed 15 March 2017)

15. Soglashenie mezhdu Pravitel'stvom Permskogo kraia, Ob"edineniem organizatsii profsoiuzov Permskogo kraia «Permskii kraisovprof» i Regional'nym ob"edineniem rabotodatelei Permskogo kraia "Sotrudnichestvo» o minimal'noi zarabotnoi plate v Permskom krae na 2017-2019 gg.: [zakliucheno v g. Permi 11.11.2016 g., № SED-01-37-89] [Agreement between the Government of the Perm region, Association of trade Union organizations of Perm region "Perm kraysovprof" and Regional Association of employers of Perm region "Cooperation" on the minimum wage in Perm region in 2017-2019], available at: http://www.consultant.ru/regbase/cgi/online.cgi?req= doc\&base $=$ RLAW368\&n=99177\#0 (accessed 5 July 2017).

Получено: 30.06.2017

Принято к печати: 18.07.2017 